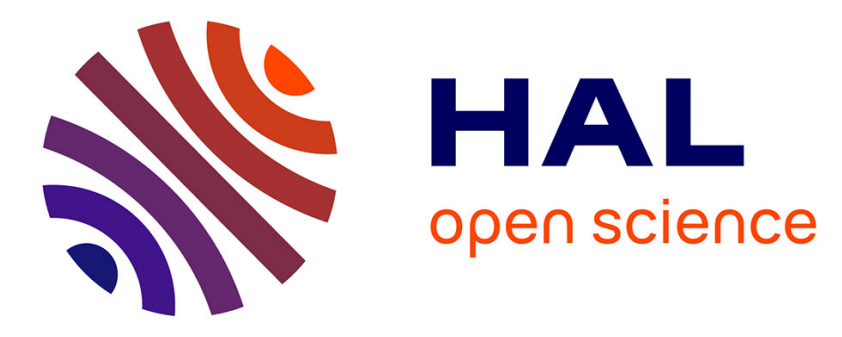

\title{
Monolithic integrated silicon-based slot-blocker for packet-switched networks
}

Guilhem de Valicourt, Miquel A. Mestre, Laurent Bramerie, Jean-Claude Simon, Eric Borgne, Laurent Vivien, Eric Cassan, Delphine Marris-Morini, Jean-Marc Fédéli, Philippe Jennevé, et al.

\section{To cite this version:}

Guilhem de Valicourt, Miquel A. Mestre, Laurent Bramerie, Jean-Claude Simon, Eric Borgne, et al.. Monolithic integrated silicon-based slot-blocker for packet-switched networks. 40th European Conference on Optical Communication (ECOC 2014), Sep 2014, Cannes, France. pp.We.3.5.5, 10.1109/ECOC.2014.6963898 . hal-01132832

\section{HAL Id: hal-01132832 \\ https://hal.science/hal-01132832}

Submitted on 18 Mar 2015

HAL is a multi-disciplinary open access archive for the deposit and dissemination of scientific research documents, whether they are published or not. The documents may come from teaching and research institutions in France or abroad, or from public or private research centers.
L'archive ouverte pluridisciplinaire HAL, est destinée au dépôt et à la diffusion de documents scientifiques de niveau recherche, publiés ou non, émanant des établissements d'enseignement et de recherche français ou étrangers, des laboratoires publics ou privés. 


\title{
Monolithic Integrated Silicon-based Slot-Blocker for Packet-Switched Networks
}

\author{
G. de Valicourt ${ }^{(1)}$, M. A. Mestre ${ }^{(1)}$, L. Bramerie ${ }^{(2)}$, J.-C. Simon $^{(2)}$, E. Borgne $^{(2)}$, L. Vivien ${ }^{(3)}$, \\ E. Cassan ${ }^{(3)}$, D. Marris-Morini ${ }^{(3)}$, J.-M. Fédéli( ${ }^{(4)}$, P. Jennevé( ${ }^{(1)}$, H. Mardoyan ${ }^{(1)}$, \\ Y. Pointurier ${ }^{(1)}$, A. Le Liepvre ${ }^{(5)}$, G. H. Duan ${ }^{(5)}$, A. Shen ${ }^{(5)}$ and S. Bigo ${ }^{(1)}$
}

(1) Alcatel-Lucent Bell Labs, Nozay, France, guilhem.de valicourt@alcatel-lucent.com

(2) Université Européenne de Bretagne, CNRS, UMR 6082 Foton Laboratory, CS 80518, 22305

Lannion, France

(3) Institut d'Electronique Fondamentale (IEF), CNRS UMR 8622, Université Paris-Sud, Orsay, France.

(4) CEA LETI, Minatec, 17 rue des Martyrs, F-38054 Grenoble cedex 9, France.

(5) III-V Lab, Joint lab of 'Alcatel-Lucent Bell Labs France', 'Thales Research and Technology' and 'CEA Leti', Campus Polytechnique, 1, Avenue A. Fresnel, 91767 Palaiseau cedex, France

Abstract We demonstrate a 16-channel, silicon-on-insulator, monolithic integrated slot-blocker. This silicon photonic circuit includes two arrayed waveguide gratings, 16 variable optical attenuators and two vertical fiber couplers. We successfully operate it with $56 \mathrm{~Gb} / \mathrm{s}$ and $80 \mathrm{~Gb} / \mathrm{s}$ QPSK optical packets.

\section{Introduction}

Switching of optical data with sub-wavelength granularity (i.e. optical packets) enables statistical multiplexing, and thus increased network efficiency, while offering the possibility to remove opto-electronic conversions at intermediate nodes. In these nodes, optical packets simply flow transparently, unless they need to be dropped; which translates into energy savings. The transparent switching fabric is the part of the nodes where this process takes place, and therefore it is an essential part of the optical packet or slot switching paradigm.

Recently, this solution has been proposed for next-generation optical mobile backhaul networks $^{2}$ and datacenters ${ }^{3}$ where highly dynamic adaptations to traffic variations as well as low-latency communication are needed. In optical slot switching (OSS) network, packets are sent into time-wavelength slots of the same

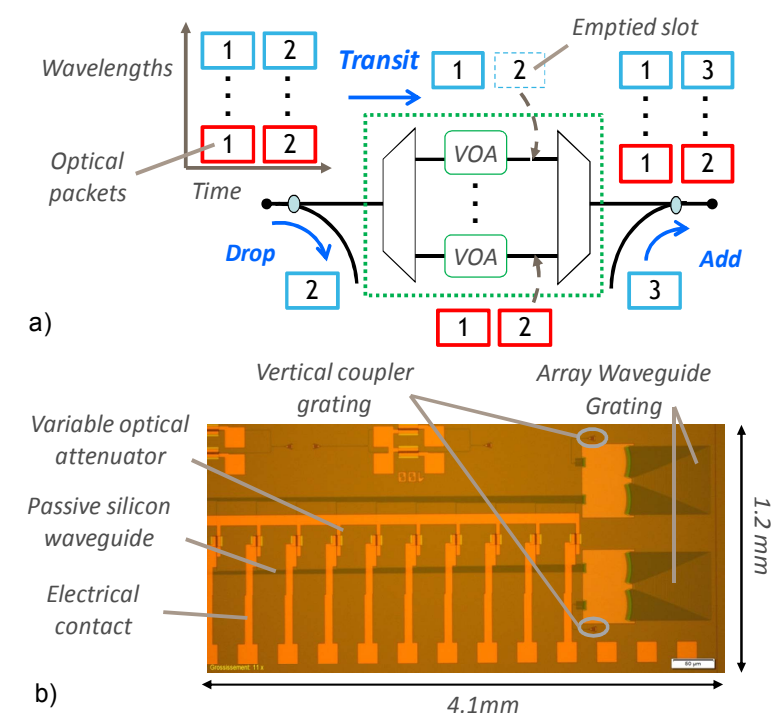

Fig. 1: slot-blocker circuit (a) schematic and (b) photography. duration and a control channel carries the headers of each synchronous slot. Today the cost of the switching fabric, or slot-blocker (SB), including wavelength (de)multiplexer and optical gates, is still high and does not meet the cost requirements of the aforementioned network segments. Photonic integrated circuits are expected to provide large cost savings. Silicon photonics is a promising option to provide largescale integration of photonic components with high-volume manufacturing compatibility. A few silicon photonic devices were proposed as optical gates, such as Mach Zehnder modulator $(\mathrm{MZM})^{4}$, ring resonator ${ }^{5}$ and variable optical attenuator (VOA) ${ }^{6}$. Integration of silicon-based VOA combined with silica arrayed waveguide grating (AWG) in order to build a $1 \times \mathrm{N}$ switching fabric (with $\mathrm{N}+1$ ports) was demonstrated ${ }^{6}$ but lacked a second on-chip AWG to provide the slot blocking functionality within a 2-port package. In addition, silicon-on-insulator (SOI)based integration of the AWGs and VOAs looks more promising to enable co-integration of the photonics and electronics in the same circuit.

In this paper, we demonstrate a novel silicon photonic solution for OSS network. A 16-channels SOI-based monolithically integrated slot-blocker was designed, fabricated and tested. We demonstrate packet-switching operation for $56 \mathrm{~Gb} / \mathrm{s}$ and $80 \mathrm{~Gb} / \mathrm{s}$ quadrature phase-shift keying (QPSK) optical packets over all channels.

\section{Devices fabrication and characterization}

Fig. 1(a) depicts the VOA-based node architecture where wavelength and packet selections are performed by the slot-blocker. To do so, a compact silicon circuit integrating two AWGs (200 GHz channel spacing), 16 highspeed VOAs and two vertical grating couplers 

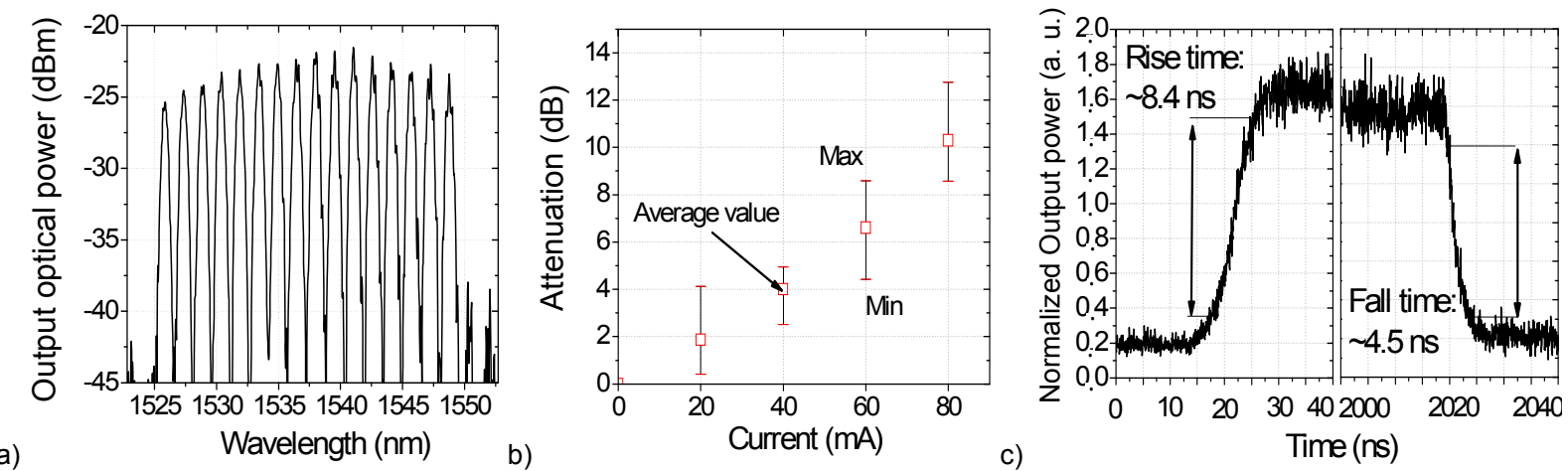

Fig. 2: (a) Output spectra after demultiplexing with $200 \mathrm{GHz}$ spacing in the fabricated device. (b) Attenuation of a VOA depending on the injected current. (c) Temporal response of the optical output.

was designed and fabricated; see Fig. 1(b). The size of the full circuit was $4.1 \mathrm{~mm} \times 1.2 \mathrm{~mm}$. The chip was fabricated in $220 \mathrm{~nm}$ overlayer SOI. First, grating couplers were patterned using $193 \mathrm{~nm}$ deep ultraviolet (DUV) lithography followed by a $70 \mathrm{~nm}$ depth Si etching. Then the fabrication of the Si waveguides and the VOA parts were carried out with two self-aligned photolithography steps followed by two Si dry etching steps. The devices were then $N$ and $P$ doped on the $100 \mathrm{~nm}$ slab of the VOA part before cladding with $1 \mu \mathrm{m}$ oxide. The electrodes were formed by DUV lithography and chlorine based reactive-ion etching. The calculated coupling efficiency of the grating couplers with a single mode fiber was around $4 \mathrm{~dB}$. The excess losses of the grating couplers were mainly due to the fabrication imperfections $(7 \mathrm{~dB}$ loss per vertical coupler, measured on a passive waveguide). The total insertion loss was around $22 \mathrm{~dB}$ which can easily be compensated with an Erbium Doped Fiber Amplifier (EDFA). The output spectra of all 16 channels are plotted in Fig. 2(a). The wavelength channels were designed with a $200 \mathrm{GHz}$ spacing from 1525.9 to $1548.8 \mathrm{~nm}$. The VOA was forward-biased in order to increase the propagation loss due to the variation of carrier concentration. Fig. 2(b) shows the attenuation as a function of the injected current for each channel; the average, maximum and minimum attenuations (across the set of gates) are represented for each value of the injection current. An average static extinction ratio (ER) higher than $10 \mathrm{~dB}$ was measured for an $80 \mathrm{~mA}$ bias current. Then a $6 \mathrm{~V}$ peak-to-peak squared electrical signal that switched every $2 \mu$ s between on and off states was applied (representing the erasure and nonerasure of $2 \mu \mathrm{s}$-long slots, respectively). The optical output power response under switching is shown in Fig. 2(c). For an average peak-topeak voltage of $6 \mathrm{~V}$, a dynamic ER of $9.7 \mathrm{~dB}$ was measured, with 10\%-90\% rise and fall times of $8.4 \mathrm{~ns}$ and $4.5 \mathrm{~ns}$, respectively. Switching time of less than $10 \mathrm{~ns}$ is well below typical slot duration of a few $\mu$ s and is sufficient for packetswitching operation, but the extinction ratio needs further improvement to allow long cascades of devices or the use of high-order modulation formats. Currently the SB was designed for a single polarization (polarization is controlled at the grating coupler input) but a polarization-independent blocker could be built following the polarization diversity approach.

\section{Experimental testbed}

We demonstrated packet-switching operation at which incoming packets were interleaved with added packets within an OSS node (Fig. 3). Two tunable lasers were used to launch a continuous-wave (CW) signal into the circuit. We used two QPSK transmitters to form continuous flows of either $56 \mathrm{~Gb} / \mathrm{s}$ or $80 \mathrm{~Gb} / \mathrm{s}$ packets (28 or 40 Gbaud) with $2 \mu$ s duration and $100 \mathrm{~ns}$ inter-

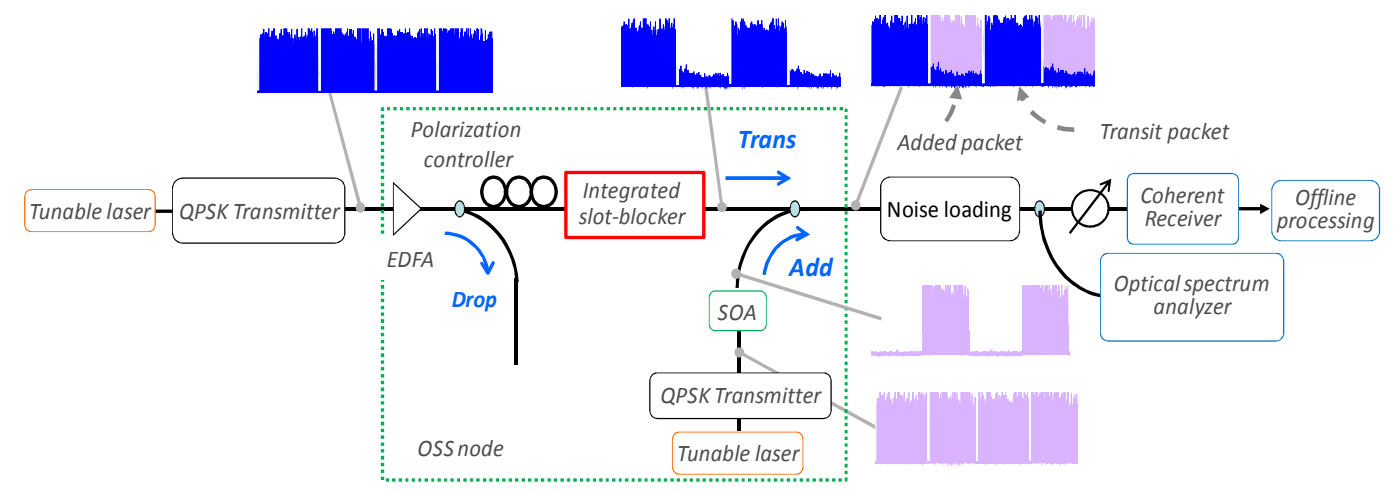

Fig. 3: Experimental set-up with QPSK optical packets under packet switching operation. 

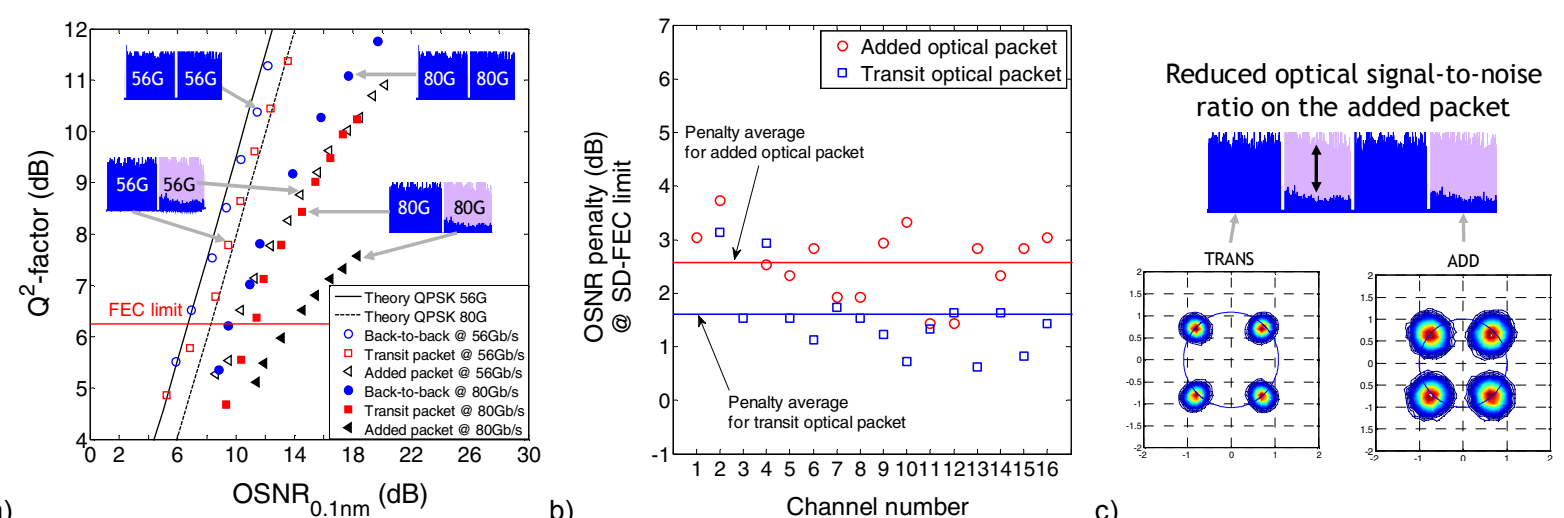

a)

b)

Channel number

c)

Fig. 4: (a) BER measurements considering the transit and the added optical packets at 56 and $80 \mathrm{Gbit} / \mathrm{s}$. (b) Impact of the channel on the transit and the added optical packets at $56 \mathrm{Gbit} / \mathrm{s}$. (c) Constellation after crossing the silicon-based slot blocker.

slot guard bands, for transit and added packets. The packet payloads contained $2^{13}-1$ de Bruijn sequences generated with independent primitive polynomials at each transmitter. The incoming signal passed through a 50/50 optical coupler and the integrated SB. Any optical packet can thus be transmitted or erased by direct modulation of a silicon-based optical gate. After the $\mathrm{SB}$, the physically emptied time slots were filled with new inserted optical packets at the same wavelength. To do so, another CW laser and a second QPSK transmitter were used, in combination with a commercial SOA which was used to block some of the packets being added. A VOA and a noise loading device were placed before the coherent receiver to adjust the optical signal-to-noise ratio (OSNR) level and the optical power of received signal. Data was stored for offline processing.

\section{Results and discussions}

Fig. 4(a) shows the $Q^{2}$-factor measurements of a sample channel obtained when varying OSNR (measured in a bandwidth of $0.1 \mathrm{~nm}$ ) for the output optical packet stream from the OSS node, when packets stem from the transit or add gates under switching. The switching regime means that half of the packets were blocked at each of the transit and add sides, leading to a stream of interleaved packets. For a $Q^{2}$-factor of $6.25 \mathrm{~dB}$, corresponding to the soft-decision forward-error-correction (SD-FEC) limit (20\% overhead), OSNR sensitivities of $6.7 \mathrm{~dB}$ and $9.5 \mathrm{~dB}$ were measured respectively for 56 and $80 \mathrm{~Gb} / \mathrm{s}$ data-rates in back-to-back. Comparing such sensitivities with transit packets, penalties of 0.7 and $1.5 \mathrm{~dB}$ were observed at 56 and $80 \mathrm{~Gb} / \mathrm{s}$, respectively. On the other hand, for added packets, penalties increased to 3.3 and $4.5 \mathrm{~dB}$ at the abovementioned data-rates under switching condition; which was attributed to the limited ER, which causes extra noise on the added packet. All channels of the integrated SB were evaluated with $56 \mathrm{~Gb} / \mathrm{s}$ QPSK optical packets. Less than $2.6 \mathrm{~dB}$ and $1.7 \mathrm{~dB}$ average channel-to-channel OSNR sensitivity penalties were obtained respectively for the added and transit packets (Fig. 4(b)). The constellations for the transit and added optical packets are presented in Fig. 4(c) and show that the limited ER of the SB did impact the integrity of the optical signal on the added packet.

\section{Conclusions}

We demonstrated a novel fully integrated silicon-photonics based slot-blocker including 2 AWGs, 16 VOAs and 2 vertical fiber couplers. We showed the good performance of the device which performs wavelength demultiplexing and multiplexing, and high-speed switching (ns timescale). We integrated the SB into a packetswitched network testbed with 56 and $80 \mathrm{~Gb} / \mathrm{s}$ QPSK optical packets and demonstrated a switching operation over all 16 channels. Our result constitutes an important milestone toward a fully integrated switching fabric. Further extinction ratio improvements are expected by increasing the VOA section length and the doping concentration.

Work supported in part by CELTIC+ SASER project.

\section{References}

[1] Y. Pointurier et al., "Dimensioning and energy efficiency of multi-rate metro networks," IEEE/OSA Journal of Lightwave Technology, vol. 30, no. 22 (2012).

[2] Q. Wei et al., "Multicast in Mobile Backhaul with Optical Packet Ring," in Proc. ST-WiMob (2013).

[3] N. Calabretta et al., "On the performance of a largescale optical Packet switch under realistic data center traffic," Opt. Commun. Netw., Vol. 5, No. 6 (2013).

[4] H.-W. Chen et al., "Forty Gb/s hybrid silicon MachZehnder modulator with low chirp," Optics Express, vol. 19, no. 2 (2011).

[5] W. Zhang et al., "Broadband Silicon Photonic PacketSwitching Node for Large-Scale Computing Systems," IEEE photon. Technol. Lett., vol. 24, no. 8, (2012).

[6] H. Nishi et al., "Monolithic Integration of a Silica-based Arrayed Waveguide Grating Filter and Silicon Variable Optical Attenuators based on p-i-n Carrier-Injection Structures," in Proc. ECOC, paper We.8.E.3 (2010). 